\title{
A LEITURA E A SUBJETIVIDADE NOS DOCUMENTOS OFICIAIS E NA FORMAÇÃO DO PROFESSOR
}

\author{
Eloisa Graziela Franco de Oliveira Hamasaki (Mestranda - PPGEL - UEL) \\ Maria Regina de Jesus Nascimento (Mestranda - PPGEL - UEL) \\ Profa. Dra. Eliana Maria Severino Donaio Ruiz (Orientadora)
}

\section{RESUMO}

Coloca-se em pauta, neste artigo, os estudos relacionados à leitura literária e à formação do leitor que tomam esta atividade em seu caráter subjetivo, como trabalho psíquico de encontro com o texto e transformação do leitor, conforme Jouve (2002) e Petit (2008). Tendo a leitura como atividade essencial a todo processo de ensino e aprendizagem, medida em avaliações de larga escala e sendo considerada por estas como entrave para $o$ avanço acadêmico da maioria dos alunos, o objetivo desse artigo, que se insere em uma pesquisa maior, é investigar comparativamente os encaminhamentos teóricometodológicos da leitura em documentos oficiais - PCN, DCE e BNCC - e quais os reflexos de tais concepções na formação inicial do futuro formador de leitor. Para tanto buscamos apreciar, além dos documentos já citados, duas entrevistas de professores da rede pública considerando a sua relação com a leitura. No decorrer do artigo, portanto, serão retomados alguns trechos dos documentos em questão, bem como das entrevistas, a fim de verificarmos se se confirma a hipótese por nós levantada de que tais aspectos da formação do leitor estão pouco contemplados nos documentos e na formação dos professores.

Palavras-chave: Leitura, subjetividade, formação do leitor.

\section{A LEITURA LITERÁRIA EM SEU CARÁTER SUBJETIVO}

Diante das inúmeras abordagens em relação ao tema leitura presentes na academia, em documentos voltados à educação, e mesmo na mídia mais geral, que passam pela diversidade de objetos que se dão a ler, pela diversidade de linguagens e suportes de que se dispõe para a leitura, etc., apontamos, neste artigo, a importância da dimensão subjetiva da leitura que tem na experiência literária lugar privilegiado.

Segundo Jouve (2013), a subjetividade na leitura se dá de forma mesmo necessária em algumas reações do leitor, quer no plano afetivo quer no intelectual. No plano afetivo, tais reações, necessariamente subjetivas, seriam, por exemplo, no que se refere às representações, ou seja, aos processos de construção de imagens mentais (de caracterização de cenários e de personagens, por exemplo) pelo leitor a partir do que o texto traz (e principalmente a partir de suas lacunas). No plano intelectual, o leitor utiliza-se de sua subjetividade ao fazer escolhas de significado diante de uma linguagem indireta, polissêmica, do texto literário, que requer criatividade e exercício mental do leitor.

Contudo, a subjetividade também pode dar-se "acidentalmente", nos dois planos já observados: afetivo e intelectual. Por meio do processo de identificação, com algum personagem em detrimento de outro, por exemplo, e muitas vezes não em conformidade 


\section{SEMINÁRIO DE PESQUISA EM CIÊNCIAS HUMANAS - SEPECH \\ Humanidades, Estado e desafios didático-científicos \\ Londrina, 27 a 29 de julho de 2016}

com o "programado" pelo texto, mas segundo critérios bem pessoais e às vezes não compreendidos, em princípio, nem mesmo pelo próprio leitor - isso se dá no plano afetivo. Intelectualmente também o leitor pode usar de sua subjetividade de maneira acidental. Jouve (2013) discorre, neste ponto, a respeito da compreensão - para a qual concorrem a memória do leitor, que retém informações de acordo com seus interesses, impossibilitado que é de guardar todas as informações de um texto em sua memória, podendo elas não serem as mais importantes para outros leitores e para o próprio autor, e a sua intertextualidade, ou seja, as relações que ele estabelece entre a leitura atual e as já feitas, de maneira também, obviamente, imprevisível por quem quer que seja (autor, editores, outros leitores, professor).

Para esse autor, quando a subjetividade se dá de forma acidental, permite um maior impacto no leitor, que se volta a si mesmo para tentar compreender a motivação das escolhas que realizou; desta forma, ao confrontar-se consigo mesmo, vai procedendo à construção de sua própria identidade. Este confronto consigo mesmo, Jouve relaciona ao espaço transicional, de Winnicott, como podemos observar em:

É, pois, em razão de sua dimensão subjetiva que a leitura se apresenta como uma exploração máxima da área transacional tal qual é definida por Winnicott. Espaço intermediário entre o eu do leitor e o não-eu do texto, entre o sujeito que lê e o outro que escreve, entre o imaginário das representações e a realidade da linguagem, ela é esse lugar intermediário onde se persegue a construção jamais acabada de nossa identidade. (JOUVE, 2013, p. 61)

Em relação a essa dimensão de transformação de si, de construção e transformação do espaço interno, Michele Petit (2008), em Os jovens e a leitura, traz importantes contribuições. A antropóloga realiza uma pesquisa envolvendo sujeitos do ambiente rural e jovens de espaços marginalizados franceses em relação à leitura. Segundo a pesquisadora, para que se aproprie do ato de ler, tirando de si o melhor proveito, seria necessário ver contemplados os variados "registros" de leitura possíveis, os quais ela procura enumerar, ainda que afirme a dificuldade de distinguir um do outro, uma vez que estão no mais das vezes imbricados.

Seriam eles: ter acesso ao saber, em atendimento tanto a uma demanda profissional ou acadêmica, quanto a uma mais pessoal, relacionada a interesses próprios e curiosidade; apropriar-se da língua, no que diz respeito a uma desenvoltura e aquisição da norma culta e também no sentido da apropriação da língua para ação, para a participação cidadã; construir-se a si próprio, sobre o qual falaremos adiante; um outro lugar, um outro tempo, em relação à hospitalidade do livro e ao sentimento, ao mesmo tempo, de acolhimento experimentado pelo leitor e de abertura para o outro; conjugar as relações de inclusão e círculos de pertencimento mais amplo são dimensões associadas à capacidade de aproximar, conciliar, universos culturais muito distintos e ao contato com uma "humanidade compartilhada" (PETIT, 2008, p. 94), com uma sensação de que mais do que pertencer a este ou àquele lugar, pertencemos ao gênero humano, o que sem dúvidas amplia demais nossos círculos de pertencimento ao mesmo tempo em que pode nos sensibilizar para o outro e romper com um possível isolamento. 


\section{SEMINÁRIO DE PESQUISA EM CIÊNCIAS HUMANAS - SEPECH \\ Humanidades, Estado e desafios didático-científicos \\ Londrina, 27 a 29 de julho de 2016}

Em relação ao terceiro registro mencionado, construir-se a si próprio, a autora demora-se um pouco mais, pois considera este aspecto muito importante e, em contrapartida, pouco conhecido, até mesmo subestimado, embora sempre mencionado por leitores profícuos. Ultrapassando a noção de língua como instrumento, Petit nos lembra que ela diz respeito à construção mesma dos sujeitos a partir de sua capacidade de simbolizar: "Quanto mais formos capazes de nomear o que vivemos, mais aptos estaremos para vivê-lo e transformá-lo. Enquanto o oposto, a dificuldade de simbolizar, pode vir acompanhado de uma agressividade incontrolada." (PETIT, 2008, p. 71).

A leitura pode então ter um papel muito rico na construção psíquica, fornecendo elementos de identificação, de simbolização, de compreensão da própria realidade, externa e interna. Aí, tem-se também a importância da literatura que pode nos levar a conhecer outras pessoas, outros lugares e ao fazê-lo nos colocar em contato conosco mesmos, dando muitas vezes voz e forma para sentimentos e sensações que antes não nos era possível compreender.

\section{ENCAMINHAMENTOS DA LEITURA NOS DOCUMENTOS OFICIAIS: PCN, DCE E BNCC}

A fim de apresentar linhas norteadoras quanto à organização curricular e planejamento de ações para a Educação Básica, sob o enfoque da demanda de uma formação cidadã, órgãos governamentais instituem documentos oficiais, dentre os quais os que trataremos neste texto, procurando observar a leitura em seu caráter subjetivo para a formação do leitor. Em âmbito nacional, o MEC apresentou, desde 1997, os Parâmetros Curriculares Nacionais (PCN) - em 1998 deu-se a publicação dos PCN para o Ensino Fundamental II, considerados neste trabalho -, no estado do Paraná houve a publicação das Diretrizes Curriculares Estaduais (DCE), e atualmente, ainda em processo de debate e elaboração, o MEC desenvolve a Base Nacional Comum Curricular (BNCC), cuja previsão de apresentação da versão final é junho de 2016, segundo o site do MEC.

Tomando-se o volume dedicado à Língua Portuguesa, tanto nos PCN quanto nas DCE, conseguimos observar uma filiação à teoria bakhtiniana no que concerne por exemplo às concepções de língua e linguagem e a questão de se considerar como unidade básica de ensino o enunciado/discurso/texto e não mais a frase descontextualizada, ainda que no caso dos PCN essa filiação não esteja discursivisada no texto, apenas constando da bibliografia, o que não ocorre nas DCE. Apontamos também como marca dessa filiação a determinação do trabalho com a maior diversidade de gêneros textuais/discursivos presentes nas práticas sociais de letramento.

Essa filiação ocorre a nosso ver em conformidade com o que nos aponta Marinho (2007): a partir da década de 1970, vai-se configurando um "discurso da inovação no ensino de Língua Portuguesa" devido a, entre outros fatores, uma mudança de paradigmas nos estudos de linguagem, com o surgimento de inúmeras teorias, como a pragmática, a análise de discurso, a linguística textual, entre outras; com isso, os documentos prescritivos da educação, como é o caso dos PCN (e os que vieram depois deles) buscam afastar-se do ensino tradicional, para alinhar-se à vanguarda científica, ou acadêmica. Vejamos cada um deles. 


\section{SEMINÁRIO DE PESQUISA EM CIÊNCIAS HUMANAS - SEPECH \\ Humanidades, Estado e desafios didático-científicos \\ Londrina, 27 a 29 de julho de 2016}

$P C N$

Os PCN da área de Língua Portuguesa (terceiro e quarto ciclos do Ensino Fundamental) apresentam-se organizados em duas partes, a primeira delas faz uma "Apresentação da área de Língua Portuguesa"; na segunda, destinada ao "Tratamento didático dos conteúdos", encontra-se a seção "Prática de escuta de textos orais e leitura de textos escritos" que é o foco de nosso interesse: os encaminhamentos relacionados à leitura.

Vemos apontadas no texto várias marcas que se referem ao caráter de mediação na formação do leitor, sendo, portanto, o professor um mediador, um parceiro na leitura e também um modelo de leitor para os alunos. De maneira geral, também parece haver uma vinculação a pressupostos de teorias cognitivas relacionadas à leitura, quando esta é referida como atividade "que implica estratégias de seleção, antecipação, inferência e verificação" (BRASIL, 1998, p. 69), por exemplo.

Deparamo-nos, contudo, como já apontado em outras pesquisas relacionadas a documentos prescritivos da educação, como por exemplo em Bueno (2007), orientações vagas, como as que preceituam que as atividades de leitura devem se diferenciar de acordo com os gêneros que contemplam ou em "selecionar situações didáticas adequadas" (BRASIL, 1998, p. 72), "desenvolvimento de novas estratégias" (BRASIL, 1998, p. 70) e até mesmo confusas, como em "é preciso agir como se o aluno já soubesse aquilo que deve aprender" (BRASIL, 1998, p. 70), o que pode vir a ocasionar um certo espontaneísmo na formação de leitores.

Além disso, pode-se depreender da leitura do documento que o contato com uma diversidade de materiais de leitura seria suficiente para formar o leitor neste nível de escolaridade, faltando, devido à vaguidão acima apontada, uma orientação mais fundamentada para a lida com os textos.

O fator que mais nos chama a atenção é o tratamento dado à literatura, ou melhor, a falta dele. No documento, o texto literário aparece entre os demais gêneros textuais, não havendo uma seção exclusiva à literatura, que considere suas especificidades, nem encaminhamentos metodológicos diferenciados.

\section{$D C E$}

As DCE de Língua Portuguesa apresentam primeiramente um texto tratando da Educação Básica, de maneira mais geral, seguido das diretrizes curriculares de Língua Portuguesa, propriamente ditas; para esta análise, nosso foco recai sobre os fundamentos teórico-metodológicos referentes à leitura e, inserida nela, à literatura, bem como sobre seus encaminhamentos metodológicos.

A escola prevista neste documento seria um espaço capaz de promover, por meio de uma gama de textos de diferentes funções sociais, ofertados pelo professor, o letramento de aluno, para que ele se envolva nas práticas de uso da língua, quer sejam de leitura, oralidade ou escrita.

Compreende-se a leitura "como um ato dialógico, interlocutivo, que envolve demandas sociais, históricas, políticas, econômicas, pedagógicas e ideológicas de determinado momento" (PARANÁ, 2008, p. 56) e assim determina-se que os encaminhamentos metodológicos dados à leitura em sala de aula visem ao aprimoramento linguístico capaz de proporcionar autonomia, capacidade leitora e, 


\section{SEMINÁRIO DE PESQUISA EM CIÊNCIAS HUMANAS - SEPECH \\ Humanidades, Estado e desafios didático-científicos \\ Londrina, 27 a 29 de julho de 2016}

consequentemente, posicionamento do aluno frente ao texto lido, efetivando-se como um co-produtor, assumindo um papel ativo no processo da leitura.

De maneira distinta dos PCN, há nas DCE tópicos específicos da literatura dispostos como único subitem da leitura. Nesse sentido a literatura dispõe além dos encaminhamentos dados à leitura uma visão voltada às funções psicológicas, formadoras e sociais, pois o documento entende literatura, conforme Candido (1972), como arte que transforma e humaniza o homem e, em consequência, a sociedade.

As DCE apontam para uma leitura em seu caráter subjetivo, ao atribuir à literatura a função psicológica, pois, considera, conforme Candido (1972), que é esta que "permite ao homem a fuga da realidade, mergulhando num mundo de fantasias, o que lhe possibilita momentos de reflexão, identificação e catarse". (PARANÁ, 2008, p. $57)$.

Os encaminhamentos metodológicos da leitura, vista em seu caráter individual, assumem explicitamente os pressupostos teóricos da Estética da Recepção e da Teoria do Efeito, para se "formar um leitor capaz de sentir e de expressar o que sentiu, com condições de reconhecer, nas aulas de literatura, um envolvimento com a subjetividade". (PARANÁ, 2008, p. 58). Ainda, preconizando o discurso como prática social, visa-se ao aprimoramento das práticas discursivas possibilitando que o aluno tenha condições de assumir uma postura mais ativa na sociedade.

Quanto à literatura, sugere-se para seus encaminhamentos metodológicos o Método Recepcional, elaborado pelas professoras Bordini e Aguiar (1993). Filiado à Teoria do Efeito e à Estética da Recepção, o método é apresentado, didaticamente, em suas cinco etapas que visam: determinar, atender, romper, questionar e ampliar o horizonte de expectativa do aluno. Consideramos que este pode ser um caminho que possibilite a reflexão, a tomada de consciência e a ampliação dos horizontes de expectativas dos alunos.

O encaminhamento mais expressivo no que se refere a uma leitura subjetiva apresentado nessa seção diz respeito a uma atividade em que o professor pode, após a leitura, estimular os alunos a projetarem-se na história e identificarem-se com algum personagem realizando, posteriormente, uma apresentação oral que justifique e defenda seu personagem.

Contudo, ao sugerir apenas um método, corre-se o risco de se fechar, restringindo as possibilidades de trabalho com o texto literário, deixando de lado, por exemplo, outras teorias como as que propõem um adensamento da implicação subjetiva do leitor.

\section{$B N C C$}

No texto introdutório do Componente Curricular Língua Portuguesa ${ }^{1}$, inserido na área de Linguagens da BNCC, são apresentados objetivos organizados em torno de cinco eixos: apropriação do sistema de escrita alfabético/ortográfico e de tecnologias da escrita; oralidade; leitura; escrita e análise linguística. Nosso foco está no eixo da leitura, para a qual são consideradas, neste texto, as dimensões da compreensão e

\footnotetext{
${ }^{1}$ Disponível em:

http://basenacionalcomum.mec.gov.br/\#/site/conhecaDisciplina?disciplina=AC_LIN\&tipoEnsino=TE_EF. Acesso em: 2 mai. 2016.
} 


\section{SEMINÁRIO DE PESQUISA EM CIÊNCIAS HUMANAS - SEPECH \\ Humanidades, Estado e desafios didático-científicos \\ Londrina, 27 a 29 de julho de 2016}

reflexão a respeito das finalidades e conteúdos dos textos lidos; das habilidades e estratégias de leitura; de efeitos de sentido que seriam provocados pelo uso de recursos linguísticos; da ampliação do vocabulário; do reconhecimento de planos enunciativos e polifonia e de reflexões sobre a temática dos textos. Há, ainda, neste texto introdutório, uma apresentação do que se espera em relação à formação literária, afirmada enquanto oferta de uma experiência estética e enquanto ampliação das "referências culturais compartilhadas nas comunidades de leitores", e a alusão ao uso social diferenciado da linguagem e consequente necessidade de um trabalho também diferenciado com esse tipo de texto.

A partir de uma concepção de língua como "forma de interação entre os sujeitos", os objetivos são considerados em relação aos campos de atuação social: práticas da vida cotidiana, práticas artístico-literárias, práticas político-cidadãs, práticas investigativas, práticas culturais das tecnologias de informação e comunicação para o Ensino Fundamental, sendo que para o Ensino Médio não se considera o primeiro destes campos, mas acrescentam-se as práticas do mundo do trabalho.

Ao percorrermos os itens de objetivos apresentados em relação a cada ano dos ensinos Fundamental e Médio, com mais detida atenção aos anos finais do Ensino Fundamental, encontramos maior quantidade de objetivos relacionados ao campo das práticas artístico-literárias, com sete objetivos para cada ano, seguido do campo das práticas político-cidadãs, com cinco objetivos do sexto ao oitavo anos e três no nono; no campo das práticas investigativas há quatro objetivos do sexto ao oitavo anos e dois para o nono ano, por fim, para os campos das práticas da vida cotidiana e das práticas culturais das tecnologias da informação e comunicação, há, respectivamente, dois e um objetivo.

No entanto, embora haja mais objetivos voltados às práticas artístico-literárias, ao lê-los reconhecemos um trabalho com a leitura num plano mais formal, de reprodução de conteúdo e reconhecimento estrutural e da tipologia dos textos; é o que vemos, por exemplo em "Relatar oralmente o enredo de obras literárias menos extensas, como contos, lendas, fábulas, mitos, reconstituindo coerentemente a sequência narrativa" e "Identificar os elementos que compõem as narrativas literárias, tais como tempo, espaço, construção dos personagens, foco narrativo, na leitura de textos da literatura juvenil, africana e indígenas", ambos objetivos do campo das práticas artístico-literárias do sexto ano.

Há uma preocupação com a construção de um repertório e a relação a uma intertextualidade, porém não no que isso potencializaria a leitura, ou a releitura, dos textos em questão. Embora fale-se da literatura enquanto constituição de subjetividades, expressão de sentimentos no texto introdutório da disciplina, consideramos que os encaminhamentos dados à leitura, de maneira geral, ficam mais no plano do reconhecimento, da passividade, faltando, à nossa vista e de acordo com uma visão de leitura a que nos propusemos na fundamentação deste artigo, espaço para $o$ posicionamento do leitor, para a expressão de sua afetividade, para o debate, enfim, para a leitura enquanto construção criativa. 


\section{SEMINÁRIO DE PESQUISA EM CIÊNCIAS HUMANAS - SEPECH \\ Humanidades, Estado e desafios didático-científicos \\ Londrina, 27 a 29 de julho de 2016}

\section{A LEITURA NA FORMAÇÃO INICIAL DO PROFESSOR}

Discutiremos a formação inicial do professor tendo em vista o panorama das entrevistas realizadas com professores de Língua Portuguesa, no que concerne à inserção destes na leitura, os dizeres de estudiosos da área e ainda os documentos já mencionados.

Em uma rápida retomada do percurso histórico da disciplina de Língua Portuguesa, verificamos que o que predominou até os anos 40 do século $\mathrm{XX}$ foi o ensino da gramática, da retórica e da poética. Isso se deu, conforme Soares (2001), devido a um fator interno à própria disciplina, ou seja, os primeiros professores responsáveis pela matéria haviam sido formados nos conhecimentos destas três áreas, isto é, eles ensinaram o que aprenderam. Nosso intuito em retomar esta questão sob a ótica histórica diz respeito a ponderarmos a importância da formação do professor, o que vale questionar, no caso específico da leitura, que professor está sendo formado para ser responsável por formar futuros leitores? Que professor se espera tendo em vista as orientações oriundas de documentos oficiais? E ainda, que professor temos em sala de aula?

Sem a presunção de dar respostas acabadas, mas com a intenção de provocar reflexões acerca da formação do professor e do perfil de professor que temos nas salas de aula, podemos considerar, primeiramente, o que nos coloca Batista (1998) sobre o baixo grau de letramento dos docentes que pode ser avaliado tanto pela representação social da leitura destes presente no discurso da imprensa e de editoras voltadas à produção do livro didático, como não leitores, quanto pelo resultado de pesquisas sobre a relação dos professores com a leitura e, até mesmo, pelos próprios formadores de professores que veem nestes certa dificuldade ou resistência na leitura de materiais elaborados na academia.

Batista (1998) apresenta algumas hipóteses que podem, no mínimo, justificar a não leitura dos professores, e nós as tomamos como passíveis de análise para, quem sabe, pensar em adequações necessárias aos encaminhamentos para a formação de leitores, que perpassam o currículo e os documentos oficiais.

Os professores são hoje, na sua maioria, segundo Batista (1998), a primeira geração de muitas famílias que conseguiram alcançar uma escolaridade de longa duração, porém a formação leitora foi confiada tão somente à escola:

Assim, os professores seriam, antes de tudo, leitores "escolares" e tenderiam a investir, mesmo em suas leituras não diretamente voltadas para escola e a prática docente, as competências e as disposições escolares, adquiridas escolarmente. (BATISTA, 1998, p. 5).

Desta maneira os professores adquiriram na escola o conjunto de conhecimentos e práticas que os levaram a ser (não)leitores e são esses mesmos conhecimentos e práticas por eles adquiridos que são por eles repassados enquanto docentes e formadores de leitores.

Podemos ver contemplado esse modo de inserção na leitura no relato de um participante de nossa pesquisa que trata da sua relação com a leitura: "Eu com a leitura? Eu acredito que fui muito obrigado a ler também, viu? A escola não desenvolveu essa paixão pela leitura não, eu fui obrigado (...) na escola a gente tinha 


\section{SEMINÁRIO DE PESQUISA EM CIÊNCIAS HUMANAS - SEPECH \\ Humanidades, Estado e desafios didático-científicos \\ Londrina, 27 a 29 de julho de 2016}

que ler pra fazer as avaliações, né?" ou em: "Eu sou um leitor tardio. Eu não sou de uma família leitora (...)” ou, ainda, em: "Bom, o interessante é que na + na escola eu nunca fui leitor". Esses professores não adquiriram o gosto pela leitura em casa, na sua infância, função esta delegada à escola. Porém esta, devido a diversos fatores, também não soube transmitir a importância da leitura a ponto de formar um leitor, pois o aprendizado escolar, conforme Nogueira (1997 apud Batista, 1998) é "mais tardio, metódico, obtido através de uma ação pedagógica explícita e ao preço de um trabalho sistemático, esforçado, árduo". Nesse sentido podemos novamente dizer que o professor ensina aquilo que aprende e acrescentar que ensina da mesma maneira que aprende.

Assim, temos que os professores, formadores de leitores, adentram às escolas sendo, na sua maioria, não leitores uma vez que a escola não desenvolve o gosto pela leitura devido a desenvolver um trabalho que não perpassa pelos anseios do aluno, sendo este podado em sua própria subjetividade, obrigado a desenvolver uma leitura que não lhe é significativa, e este mesmo modo de ensinar acaba sendo perpetuado. Ressaltamos por exemplo, na primeira fala trazida a este artigo, o uso da palavra também pelo professor referindo-se à obrigatoriedade da leitura a que foi submetido, o que nos leva a inferir que o mesmo vê tal obrigatoriedade da leitura na sua prática docente ou na escola, em geral.

Ainda conforme Batista (1998), as relações e as disposições da leitura docente seriam "parte de um processo de exclusão tardia ou de inclusão relativa" (BATISTA, 1998 , p. 21), visto que, mesmo os professores tendo acesso à leitura, isto não lhes confere uma pronta inclusão cultural, pois devido a sua leitura ser tida como leitura escolar esta não o proveria do discernimento necessário para avaliar a legitimidade de uma obra, levando a leituras com baixa legitimidade cultural, ou seja, leituras de pouco prestígio ou simplesmente voltadas ao fazer pedagógico. Avaliamos tal questão no dizer da professora, colaboradora da pesquisa, ao se referir à sua relação com a leitura: “(...) Eu leio, mas literatura mesmo é o que eles leem, aí você a gente lê lógico porque daí a gente vai fazer um trabalho, procuro ler o que eles leem, mais direcionado à aula, mesmo".

Tendo em consideração o já exposto e o que nos colocam os documentos oficiais quanto ao professor ser capaz de propiciar análise crítica, selecionar conteúdo, promover amadurecimento, domínio discursivo e capacidade leitora e, entre outras aptidões, não se reduzir a transmitir conhecimento, mas sim produzi-lo, podemos dizer que, na atualidade, o professor ainda não está sendo formado para ser um formador de leitor. Nesse caso, haveria necessidade de uma complementação na formação para que o professor possa compreender e usar em sala de aula os fundamentos teóricos de uma proposta segundo o que pedem os documentos e ser um professor portador de mudanças tão necessárias, principalmente, no que diz respeito à leitura em seu caráter subjetivo, levando os alunos a gostarem de ler e a serem verdadeiros leitores.

Ainda vale considerarmos Silva (2005) que nos alerta para o faz-de-conta que acontece na escola, local onde o discurso mostra a importância irrefutável da leitura no processo de escolarização, mas na prática as condições de trabalho não condizem com o discurso apresentado. Nesse sentido, tal contradição perpassa pela formação inicial e continuada do professor que não estimula um leitor assíduo que realmente usufrua da complexidade do ato de ler. 


\section{SEMINÁRIO DE PESQUISA EM CIÊNCIAS HUMANAS - SEPECH \\ Humanidades, Estado e desafios didático-científicos \\ Londrina, 27 a 29 de julho de 2016}

\section{PALAVRAS FINAIS}

No decorrer deste artigo, buscamos, antes de tudo, considerar a importância da leitura voltada para a subjetividade do aluno, isto por acreditarmos que para formar um leitor competente, que tenha uma relação mais implicada com a leitura, o ensino da leitura deve considerar a construção psíquica da intimidade do próprio leitor.

Observamos, no entanto, que ainda se tem um longo caminho a percorrer em busca de uma formação de leitores, sob esse viés. Isto porque, além de essa perspectiva ser pouco ou quase nada contemplada na formação inicial e nos documentos oficias, o que se tem normalmente chega ao professor (em geral, um leitor escolar) muitas vezes de forma deficitária via formação continuada.

Se a função da escola é inserir o aluno no mundo da leitura e da escrita, tornando-o um cidadão letrado e garantindo seu acesso a um direito tão relevante quanto a leitura literária, é chegada a hora, para não dizer passada, de uma melhor formação e melhor encaminhamento do que se dizem ser as práticas de leitura.

\section{REFERÊNCIAS BIBLIOGRÁFICAS}

BATISTA, Antônio Augusto Gomes. A leitura incerta: a relação de professores(as) de Português com a leitura. Educação em Revista, Belo Horizonte, n. 27, jul. 1998. Disponível em: <http://fundacaotidesetubal.org.br/midia/sugestao_leitura_274.pdf $>$. Acesso em: 17 mai. 2016.

BRASIL. Secretaria de Educação Fundamental. Parâmetros curriculares nacionais: terceiro e quarto ciclos do ensino fundamental: Língua Portuguesa. Brasília, $\mathrm{MEC} / \mathrm{SEF}, 1998$.

BUENO, Luzia. A construção de representações sobre o trabalho docente: o papel do estágio. 2007. 205 fls. Tese (Doutorado em Lingüística Aplicada e Estudos da Linguagem) - Pontifícia Universidade Católica de São Paulo, São Paulo, 2007.

JOUVE, Vincent. A leitura como retorno a si: sobre o interesse pedagógico das leituras subjetivas. In: ROUXEL, Annie; LANGLADE, Gérard; REZENDE, Neide Luzia de. (Org.). Leitura subjetiva e ensino de literatura. São Paulo: Alameda Casa Editorial, 2013. p. 53-65.

KLEIMAN, Angela. Leitura: ensino e pesquisa. 4 ed. Campinas: Pontes Editores, 2011.

MARINHO, Marildes. Currículos da escola brasileira: elementos para uma análise discursiva. Revista Portuguesa de Educação, Braga, v. 20, n. 1, p. 163-189, 2007. Disponível em: <www.scielo.mec.pt/pdf/rpe/v20n1/v20n1a07.pdf>. Acesso em: 29 set. 2015.

PARANÁ, Secretaria de Estado de Educação. Diretrizes Curriculares da Educação Básica - Língua Portuguesa. Paraná, 2008. 


\section{SEMINÁRIO DE PESQUISA EM CIÊNCIAS HUMANAS - SEPECH \\ Humanidades, Estado e desafios didático-científicos \\ Londrina, 27 a 29 de julho de 2016}

PETIT, Michèle. Os jovens e a leitura: uma nova perspectiva. São Paulo: Editora 34, 2008.

SILVA, Ezequiel Theodoro da. Elementos de pedagogia da leitura. 3 ed. São Paulo: Martins Fontes, 1998.

SOARES, Magda. Que professor de português queremos formar. Boletim da ABRALIN - Associação Brasileira de Linguística, Brasília n. 25, ago. 2001. Disponível em: <http://www.unb.br/abralin/index.php?id=8\&boletim=25\&tema=13>. Acesso em: 5 out. 2015. 